\title{
A influência das brincadeiras no desenvolvimento do Pensamento Computacional
}

\author{
Tamara Cristina Ferreira ${ }^{1}$, Joslaine Cristina J. de Freitas ${ }^{1}$, \\ Marcos Wagner de Souza Ribeiro ${ }^{1}$ \\ ${ }^{1}$ Instituto de Ciências Exatas e Tecnológicas \\ Universidade Federal de Jataí \\ 758101-615 - Jataí - GO - Brazil \\ \{mhara92cinder, joslaine, marcoswagnersouza\}@gmail.com
}

\begin{abstract}
During childhood, children are influenced by the environment, and playful activities often reinforce this influence, with stereotypes of female and male roles. If some toys reinforce gender stereotypes, can this help in choosing the area of performance? This work is configured in the development of a questionnaire, applied to students from different areas of knowledge, in order to answer the aforementioned question, as well as its relationship with the development of skills inherent to Computational Thinking.
\end{abstract}

Resumo. Durante a infância, as crianças sofrem influências do meio e, as atividades lúdicas, muitas vezes reforçam essa influência, com esteriótipos de papéis femininos e masculinos. Se alguns brinquedos reforçam estereótipos de gênero, este pode auxiliar na escolha da área da atuação? Este trabalho, configura-se no desenvolvimento de um questionário, aplicado a discentes de áreas do conhecimento distintas, com o objetivo de responder a questão supracitada, bem como sua relação com o desenvolvimento de habilidades inerentes ao Pensamento Computacional.

\section{Introdução}

Segundo [Finco 2003], desde os primeiros anos de vida da criança, existe uma vigilância exercida não só pela família, mas também pela escola para que se possa garantir a manutenção de uma masculinidade ou feminilidade considerada hegemônica. Deste modo, [Bichara 2001] alega que brincadeiras por mais fantasiosas que sejam, atuam como um poderoso agente da estereotipia de gênero. E, no processo de construção da lógicamatemática, a criança sofre interferência do meio por intermédio das brincadeiras e na construção das estruturas da inteligência, essas fornecem fundamentos da lógica e da matemática [Aranão 1996]. Contudo, esses fatos levaram as seguintes indagações: as brincadeiras e brinquedos que reforçam uma estereotipia de gênero, podem influenciar na construção da abstração de problemas? As brincadeiras femininas, por reforçarem o "papel da mulher", induzem na maior representação das mulheres em cargos considerados femininos, como educação, saúde e assistência social?

Este trabalho tem como objetivos específicos: (a) desenvolver um questionário, baseado nas perguntas sobre níveis de abstração, utilizadas por [Ferreira et al. 2019]; (b) aplicar o questionário à discentes de graduação e tecnologia de ambos os sexos, mas de áreas distintas; (c) delinear as brincadeiras preferidas na terceira infância dos discentes; 
e (d) delinear o nível de desenvolvimento de habilidades voltadas à abstração de cada discente. Por fim, o objetivo geral deste trabalho é avaliar se as brincadeiras da terceira infância, podem influenciar no desenvolvimento de habilidades voltadas ao Pensamento Computacional (PC) que por sua vez, pode implicar no baixo índice de mulheres na área das exatas em relação as demais.

\subsection{Pensamento Computacional}

O crescimento do comércio de computadores a partir do século 20, forçou uma revolução na literacia digital que tornou-se uma habilidade essencial para ter sucesso em nosso complexo mundo digital do século 21. Na era digital, compreender o funcionamento lógico dos computadores e obter habilidades para resolver problemas complexos, é um diferencial. Em decorrência disso, a Base Nacional Comum Curricular (BNCC) já apresenta o ensino de Computação com o foco no Pensamento Computacional de forma estrita, por estar integrado à Matemática. O PC remonta ao trabalho construcionista de Seymour Papert e foi cunhado como um termo em um artigo seminal de [Wing 2006], onde a autora determina o PC como a reformulação de um problema aparentemente difícil, em outro que talvez possa resolver - por meio de redução, incorporação, transformação ou simulação.

\section{Metodologia}

Com o intuito de avaliar as brincadeiras preferidas dos indivíduos do sexo feminino e do sexo masculino durante a infância, bem como verificar se estas brincadeiras influenciam na escolha da área de atuação, foi desenvolvido um questionário com perguntas sociodemográficas (sexo, idade, brincadeira preferida na terceira infância e área do conhecimento do aluno) e questões voltadas aos conhecimentos sobre o PC (abstração e generalização).

\subsection{Questionário}

O questionário contém três seções que estão dividades como se segue:

- 10 seção - 3 questões sociodemográficas;

- $2^{\mathbf{0}}$ seção - 1 questão sobre a área de conhecimento;

- $3^{0}$ seção - 4 questões sobre PC.

Solicitou-se que cada participante selecionasse três brincadeiras preferidas que se deu pelo entendimento que escolher somente uma brincadeira dentre diversas que a criança brincou, durante um período de 6 anos - já que as brincadeiras preferidas mudam de acordo com o tempo, seria impossível. Já as questões sobre PC, foram admitidas três questões sobre abstração ${ }^{1}$ e uma questão sobre generalização ${ }^{2}$ que é considerado o segundo passo após a abstração.

\section{Resultados e Discussão}

O questionário foi respondido por 182 discentes, sendo 44 da área de Ciências Agrárias (35 do sexo feminino e 9 do sexo masculino), 18 de Ciências Biológicas (13 do sexo feminino e 5 do sexo masculino), 35 de Ciências da Saúde (28 do sexo feminino e 7 do sexo masculino), 56 de Ciências Exatas e da Terra (22 do sexo feminino e 34 do sexo

\footnotetext{
${ }^{1}$ Questões 2, 3 e 4 do questionário usado no trabalho de [Ferreira et al. 2019]

${ }^{2}$ Questões 5 do questionário usado no trabalho de [Ferreira et al. 2019]
} 
masculino) e 29 de Ciências Humanas (20 do sexo feminino e 9 do sexo masculino). A diferença entre os sexos de acordo com a área, pode ser observada no gráfico contido na Figura 1, onde aponta uma maior representação feminina - 64\% do total de participantes - com exceção da área de Ciências Exatas.

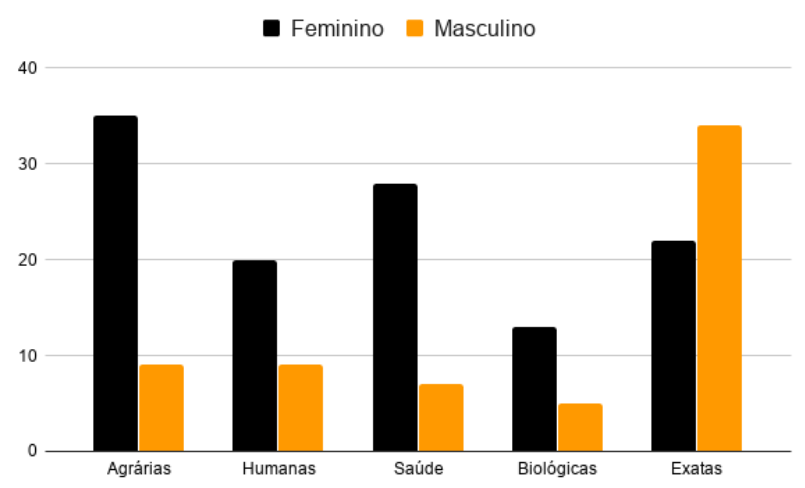

Figura 1. Quantidade de discentes em cada área - por sexo

Com relação as brincadeiras preferidas, na área de Ciências da Saúde, 10 discentes do sexo feminino escolheram boneca (35,71\%); 8 escolheram Escolinha (28,57\%); e 9 escolheram Barbie (32,14\%) e em relação aos discentes do sexo masculino, 5 escolheram Futebol (71,42\%); 5 escolheram videogame (71,42\%); e 4 escolheram Bicicleta (57,14\%). Na área de Ciências Biológicas, 6 discentes do sexo feminino escolheram Casinha e Queimada (46,15\%); e 5 escolheram Bicicleta $(38,46 \%)$ e em relação aos discentes do sexo masculino, 4 escolheram Futebol (80\%) como a brincadeira mais votada; e Bicicleta, Queimada e Boneco de Heróis tiveram 2 votos (40\%). Na área de Ciências Humanas, 8 discentes do sexo feminino escolheram Esconde-esconde (40\%); 7 escolheram Rouba bandeira (35\%); e 7 escolheram Escolinha (35\%) e em relação aos discentes do sexo masculino, 6 escolheram Bicicleta (66,67\%); 4 escolheram Futebol (44,44\%); e 4 escolheram videogame (44,44\%). Na área de Ciências Agrárias, 17 discentes do sexo feminino escolheram Esconde-esconde (48,57\%), 13 escolheram Bicicleta $(37,14 \%)$ e 11 escolheram Queimada $(31,42 \%)$ e em relação aos discentes do sexo masculino, 5 escolheram Futebol (55,56\%); 4 escolheram Carrinho (44,44\%); e 4 escolheram videogame $(44,44 \%)$. Na área de Ciências Exatas e da Terra, 9 discentes do sexo feminino escolheram Esconde-esconde (70,91\%); 8 escolheram Bicicleta (36,36\%); e 7 escolheram Queimada $(31,82 \%)$ e Casinha $(31,82 \%)$ e em relação aos discentes do sexo masculino, 22 escolheram videogame (64,71\%), 14 escolheram Esconde-esconde (41,18\%) e 10 escolheram bicicleta $(29,41 \%)$.

Com relação ao nível de desenvolvimento do Pensamento Computacional, as questões referente a abstração - mesmo considerado o pilar do PC, foram adotadas menor peso:

- $1^{\circ}$ questão sobre abstração - equivale a $23 \%$ do total;

- $2^{\circ}$ questão sobre abstração - equivale a $23 \%$ do total;

- $3^{\circ}$ questão sobre abstração - equivale a $23 \%$ do total; e

- $4^{\circ}$ questão sobre generalização - equivale a $31 \%$ do total. 
Pode-se observar no gráfico contido na Figura 2 que o desenvolvimento do PC dos discentes do sexo masculino que cursam graduação ou tecnologia, na área de Ciências Exatas, é relativamente igual comparado às discentes do sexo feminino. Esses dados podem auxiliar a pesquisa de [Ferreira et al. 2019] que evidenciou um desempenho relativamente igual entre discentes do curso de Ciências da Computação em ambos os sexos. Além disso, os dados mostraram que as brincadeiras preferias das discentes do sexo feminino, tanto eram realizadas em espaços urbanos, quanto brincadeiras que induzem ao "papel da mulher na sociedade". Nas áreas das Ciências da Saúde, as discentes do sexo feminino possuem um desenvolvimento do PC de 58,82\% - inferior em relação ao sexo masculino. Relacionando com as brincadeiras preferidas na segunda infância, duas brincadeiras preferidas, são consideradas brincadeiras que reforçam o papel da mulher na sociedade, como por exemplo a Barbie que sua marca cor-de-rosa induz a certas formas de pensar, agir e se relacionar, mostrando modos de "ser menina"[Cechin and Silva 2012], já a da boneca estimula ao cuidado com o outro, desde muito cedo.

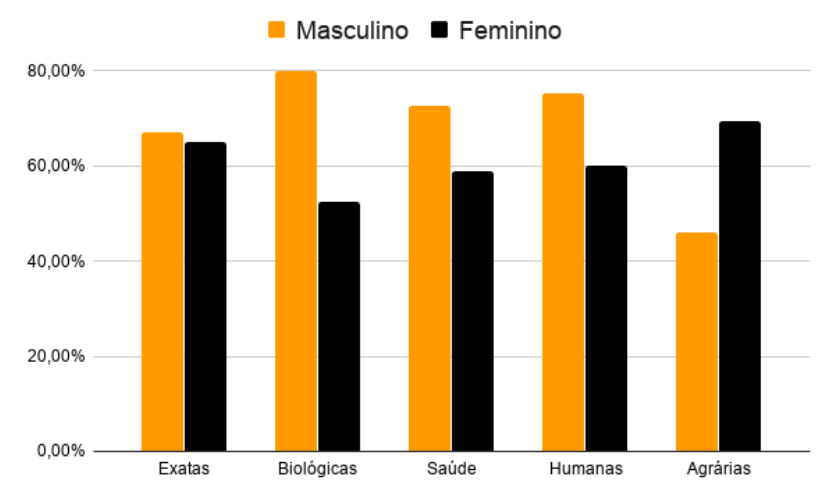

Figura 2. Desenvolvimento do PC de acordo com o sexo

Nas ciências Agrárias, observa-se que as discentes do sexo feminino tiveram um desenvolvimento de PC superior de $69,48 \%$, em relação ao sexo masculino. Observa-se que todas as brincadeiras (Esconde-esconde, Bicicleta e Queimada), são realizadas preferencialmente em espaços urbanos ou com grande extensão e que envolvem mais crianças [Alves et al. 2014]. Na área das Ciências Humanas, o desenvolvimento do PC das discentes do sexo feminino foi de $60 \%$, relativamente igual ao PC das discentes da área da saúde $(58,82 \%)$ e relacionando o PC com as brincadeiras, observa-se que duas brincadeiras preferidas envolvem a participação de mais crianças e normalmente são realizadas em espaços urbanos, onde a estrutura apresentada nesses espaços e sua disposição, podem influenciar na construção de habilidades sociais, atuando sobre a socialização [Luz and Kuhnen 2013]. Já brincar de Escolinha, pode induzir a criança sobre os conhecimento de lecionar e aprender, e o mesmo se aplica às escolhas das discentes da área de Ciências Biológicas que tiveram um desenvolvimento de PC de 52,60\% e escolheram duas brincadeiras realizadas em espaços urbanos, bem como Casinha que utiliza a realidade do dia a dia na criação de um mundo imaginário, como cozinhar, fazer lição de casa, hora de dormir, entre outras tarefas [Alves et al. 2014].

Observa-se que em quase todos os casos, os meninos escolhem brincadeiras que em sua maioria são brincadas em aspaços urbanos, com exceção do videogame que aparece em quase todas as áreas como uma das brincadeiras preferidas entre os discentes do 
sexo masculino e de acordo com [Martinez 2009], durante a década de 60, os "avanços da microeletrônica, a mulher no mercado de trabalho e a redução dos espaços públicos para crianças"contribuíram para o sucesso dos videogames. Além disso, os jogos contemplam os aspectos como processamento, tomadas de decisões e de noções de estratégias para solução de problemas [Munguba et al. 2012].

\section{Conclusão}

Conclui-se que os discentes do sexo masculino em sua totalidade, utilizaram brinquedos que tanto auxiliam no desenvolvimento de noções de resolução de problemas e estratégias quanto brincaram em espaços abertos, enquanto as discentes do sexo feminino, em sua maioria, mesmo que algumas brincadeiras preferidas também incluem espaços urbanos, as brincadeiras em comum a maioria, induzem ao "papel da mulher" como cuidadora (brincar de casinha, boneca, etc), influenciando na escolha da área profissional. Esta pesquisa pôde mostrar que o desenvolvimento de habilidades de abstração do PC, pode sofrer influência das brincadeiras e/ou brinquedos utilizados na infância. Para trabalhos futuros, pretende-se expandir a pesquisa de tal forma a desenvolver um questionário que possa ser aplicado à crianças e adolescentes para analisar o $\mathrm{PC}$ desde os primeiros anos escolares. Além disto, desenvolver um estudo a fim de inserir brincadeiras nos anos escolares iniciais para aumentar a participação feminina na área de computação.

\section{Referências}

Alves, C., Camara, A. R., Geraldin, C., and Martins, I. C. (2014). Políticas públicas de lazer: jogos, brinquedos e brincadeiras de crianças em praças, na cidade de araras. Revista Mackenzie de Educação Física e Esporte, 13(2).

Aranão, I. V. D. (1996). A matemática através de brincadeiras e jogos. Papirus Editora.

Bichara, I. D. (2001). Brincadeiras de meninos e meninas: segregação e estereotipia em episódios de faz-de-conta. Temas em Psicologia, 9(1):19-28.

Cechin, M. B. C. and Silva, T. d. (2012). Assim falava barbie: uma boneca para todos e para ninguém. Fractal: Revista de Psicologia, 24(3):623-638.

Ferreira, T., de Freitas, J. C. J., Ribeiro, M. W. S., and Raimann, E. (2019). Desenvolvimento do pensamento computacional na ciência da computação-uma questão de gênero? In Anais do Workshop de Informática na Escola, volume 25, page 944.

Finco, D. F. (2003). Relações de gênero nas brincadeiras de meninos e meninas na educação infantil. Pro-posições, 14(3):89-101.

Luz, G. M. d. and Kuhnen, A. (2013). O uso dos espaços urbanos pelas crianças: explorando o comportamento do brincar em praças públicas. Psicologia: reflexão e crítica, 26(3):552-560.

Martinez, V. C. V. (2009). "o brincar e a realidade"... virtual: videogame, assassinatos e imortalidade. Estilos da Clínica, 14(26):150-173.

Munguba, M. C., Valdés, M. T. M., de Matos, V. C., and da Silva, C. A. B. (2012). Jogos eletrônicos: apreensão de estratégias de aprendizagem. Revista Brasileira em Promoção da Saúde, 16(1):39-48.

Wing, J. M. (2006). Computational thinking. Communications of the ACM, 49(3):33-35. 